\title{
Vitamin D deficiency among new diagnosed tuberculosis patients in Sudan
}

\author{
Habab M. YASSIN ${ }^{1,2}$ \\ 1. Biology department, Faculty of Science, King Khalid University, Abha, Saudi Arabia \\ 2. Microbiology \& Microbial technology, Faculty of science \& technology, Alneelain university, \\ Khartoum, Sudan \\ * E-mail of the corresponding author: hbabakr@kku.edu.sa
}

\begin{abstract}
Tuberculosis infection has been associated with vitamin D deficiency, previous studies suggest relationships between low levels of vitamin D and the incidence and severity of tuberculosis. Although individuals living in Sudan have a continuous exposure to sunlight, the source of vitamin D, tuberculosis is still one of the major health problem in the country. Vitamin D play a major role in the function of the macrophage, key factor in host resistance to tuberculosis.

The objective of this study was to determine the prevalence of vitamin D deficiency in newly diagnosed tuberculosis (TB) patients compared to healthy cohort.

This is a hospital based case control study, conducted at Alshaab hospital. Blood samples were collected from new diagnosed smear positive pulmonary TB patients, and community controls. Serum 25(OH)-vitamin D3 was determined by an Enzyme Linked Immunosorbent Assay technique. A serum level of 25(OH)-vitamin D3 below $<20 \mathrm{ng} / \mathrm{ml}$ was defined as vitamin D deficiency.

The prevalence of vitamin D deficiency was found to be higher in TB patients $(89.3 \%)$ than in community controls $(57.2 \%, \mathrm{P}=0.004)$. The mean $25(\mathrm{OH})$ vitamin $\mathrm{D} 3$ level of TB patients was significantly lower $(21.76 \pm 3.3 \mathrm{ng} / \mathrm{ml})$ than community healthy controls $(30.5 \pm 2.91 \mathrm{ng} / \mathrm{ml}, \mathrm{P}=0.005)$.

Vitamin D was found to be the lowest in patients with severe symptoms, and in patients who were subjected or exposed to $\mathrm{Tb}$ risk factors such as smoking or consuming poor vitamin $\mathrm{D}$ dietary.

Conclusion: Vitamin D deficiency was found to be prevalent among new diagnosed TB patients. More studies are needed to determine the effect of vitamin D supplementation in the prevention and management of tuberculosis in Sudan.
\end{abstract}

Keywords: key words, Vitamin D; deficiency; tuberculosis; Sudan

DOI: $10.7176 / \mathrm{JBAH} / 9-24-08$

Publication date: December $31^{\text {st }} 2019$

\section{Introduction}

In the manufacturing sector today, human capital is still essential for most factories to carry out a variety of manual operations, in spite of the rapid advancement of automation technology and robotics. Futuristic vision of "unmanned manufacturing" (Deen 1993) is forbiddingly expensive, because all its hardware components need to be computer controlled so as to freely communicate with each other; and yet, most of the outcomes are not promising (Sun \& Venuvinod 2001). By and large, factories equipped with relatively simple machinery contr Human tuberculosis is an infectious disease caused by Mycobacterium tuberculosis (TB) that belong to the $M$. tuberculosis complex (Jones et al., 1993; Kumar et al., 2007). Tuberculosis is a major public health problem in many countries world wide and is of significance in developing countries. World health organization (WHO) reported that 9.6 million TB cases occurred, and 1.5 million people died because of TB worldwide in 2014 (WHO, 2015).

Host susceptibility to TB infection depends on environmental factors (Borkow et al., 2001), genetic factors (Kramnik et al., 2000), as well as hot-pathogen interaction. Cell- mediated immunity plays a major role in protection against mycobacteria infection (Rook \& Zumla, 2001). The association of vitamin D deficiency and TB has been reported from different populations, Vitamin D affect the immune response to tuberculosis, by playing a role in the function of macrophages, an important cell in host resistance in tuberculosis. Vitamin D deficiency caused increased replication of Mycobacterium bovis in mice (Waters et al., 2004). Other studies showed that 
vitamin D enhances phagolysosome fusion and induces a superoxide burst in Mycobacterium tuberculum bacteria infected macrophages (Hmama et al., 2004; Lee et al., 2009). Not only vitamin D level, but also polymorphisms in the vitamin D receptor influence host susceptibility to TB (Samir, 2011).

Serum vitamin D level differ significantly between populations, several geographical and cultural factors influenced these levels. Although individuals living in Sudan have a great chance of exposure to sunlight; which is the important source of vitamin D, TB is a devastating disease with a great burden in Sudan that affects the economy and the productive population. Studies relating to the role of vit D in Sudanese TB are scares.

The aim of this study was to determine the prevalence and associated factors of vitamin D deficiency in new diagnosed TB patients compared to $\mathrm{Tb}$ free cohort.

\section{Material and Methods}

It was hospital based case control study, conducted at Alshaab hospital.

Consecutive sixty newly diagnosed smear or x-ray positive untreated tuberculosis patients were enrolled in this study. In addition, one hundred and four age and sex matched healthy individuals were included as controls. Patients knows to be immunosuppressed (because of human immunodeficiency virus, pregnant ladies or patients under corticosteroid therapy) or had previous TB infection were excluded. Informed written consent was taken from all participants.

Demographic data and information's regarding TB risk factors were collected into a predesigned questionnaire. Data on age, sex, occupational status, level of education, alcohol intake and smoking were collected from all newly diagnosed TB patients and controls. Patients with past and present history of anti-tuberculous drugs who have discontinued the drugs because of unknown reason, chronic cases of pulmonary tuberculosis, drug defaulter, and extra pulmonary tuberculosis were excluded from the study.

Two to three $\mathrm{ml}$ of venous blood was collected into plain containers, centrifuged at $3000 \mathrm{rpm}$ for 10 minutes, serum was collected in new containers and stored at $-20 \mathrm{C}$ for measurement of vit D concentrations.

Euroimmun ELISA kit was used to measure 25-OH vitamin D concentration following manufacture instructions. The normal, insufficiency and deficiency of Vitamin D3 were defined as; normal levels ( $>30 \mathrm{ng} / \mathrm{dl})$, vitamin D3 insufficiency $(20-30 \mathrm{ng} / \mathrm{ml})$ and vitamin D3 deficiency $(<20 \mathrm{ng} / \mathrm{ml})$. This study was Ethically approved by the ethics committee of the institute of Endemic Diseases. Data was analyzed on SPSS (statistical packaged for social science) version 24.0. Frequency and chi square test were used to compare means. The significant $p$-value was taken at $\leqslant 0.05$

\section{Results}

Sixty newly diagnosed Tuberculosis patients were enrolled in this study. The male: female ratio was 3:1 their mean age was $42 \pm 17.3$ (ranged from 20 to 72 years). Their mean weight was $(55.9 \pm 14.3) \mathrm{kg}$. One hundred and four age and sex matched volunteers were also enrolled as controls, their mean weight was $69.9 \pm 15.9 \mathrm{~kg}$. Some sociodemographic data are shown in table 1.

The mean \pm S.D of 25-hydroxyvitamin D3 in cases and controls were $21.76 \pm 3.3$ and $30.5 \pm 2.91 \mathrm{ng} / \mathrm{ml}$ respectively, $(\mathrm{p}=0.0001)$. The normal, insufficiency and deficiency of 25 - hydroxyvitamin D3 were observed in 9 $(15 \%), 15(25 \%)$ and $36(60 \%)$ in each case respectively compared to controls as $61(58.7 \%), 31(29.8 \%)$ and 12 $(11.5 \%)$ respectively. 
Table 1: Socio-demographic of the study participants $(n=164)$

\begin{tabular}{|llll|}
\hline Variables & $\begin{array}{l}\text { TB patients } \\
(\mathbf{n}=6 \mathbf{6})\end{array}$ & $\begin{array}{l}\text { Controls } \\
\mathbf{( n = 1 0 4 )}\end{array}$ & P. value \\
$\mathbf{N}(\mathbf{\%})$ & $\mathbf{N}(\mathbf{0})$ & \\
\hline Gender & & & \\
Male & $42(70)$ & $76(73.1)$ & \\
Female & $18(30)$ & $28(26.9)$ & $>0.05$ \\
Age & $42 \pm 17.3$ & $46 \pm 16.2$ & $>0.05$ \\
Weight & $55.9 \pm 14.3$ & $69.9 \pm 15.9$ & 0.037 \\
Occupation & & & \\
Employed & $4(7)$ & $39(38)$ & \\
Unemployed & $18(30)$ & $19(18.3)$ & \\
Labor & $22(37)$ & $32(30.8)$ & \\
Others & $16(27)$ & $14(13.4)$ & 0.041 \\
\hline Smoking & & & \\
Yes & $26(43.3)$ & $17(15.4)$ & \\
No & $34(56.7)$ & $87(84.6)$ & 0.03 \\
\hline
\end{tabular}

All comparisons were found statically significant, and vitamin D deficiency was found to be more prevalent in TB patients $(60 \%)$ compared to community controls $(11.5 \%, \mathrm{P}=0.004)$ as shown in table 2 .

Table 2: Frequency of 25-hydroxyvitamin D3 in TB cases and controls $(n=164)$

\begin{tabular}{|llll|}
\hline & $\begin{array}{l}\text { Tb cases } \\
\mathrm{N}(\%)\end{array}$ & $\begin{array}{l}\text { Controls } \\
\mathrm{N}(\%)\end{array}$ & $\begin{array}{l}\mathrm{P} . \\
\text { value }\end{array}$ \\
\hline $\begin{array}{l}\text { Normal levels } \\
(>30 \mathrm{ng} / \mathrm{ml})\end{array}$ & $9(15 \%)$ & $61(58.7 \%)$ & 0.001 \\
$\begin{array}{l}\text { Insufficiency } \\
(20-30 \mathrm{ng} / \mathrm{ml})\end{array}$ & $15(25 \%)$ & $31(29.8 \%)$ & 0.01 \\
$\begin{array}{l}\text { Deficiency } \\
(<20 \mathrm{ng} / \mathrm{ml})\end{array}$ & $36(60 \%)$ & $12(11.5 \%)$ & 0.004 \\
Total & 60 & 104 & \\
\hline
\end{tabular}

Most of the patients were diagnosed as having pulmonary TB. Symptoms presented in the majority of cases were the triad of cough, fever and loss of weight, and the most common clinical findings among cases were wasting and fever. 25-hydroxyvitamin D3 concentration was found to be the lowest in patients presented the above symptoms collectively (Table 3 ). Other symptoms include chest pain, lymph node swelling and loss of appetite. 
Table 3: Frequency of some clinical symptoms and 25-hydroxyvitamin D3 concentration among studied TB patients $(\mathbf{n}=60)$

\begin{tabular}{|lll|}
\hline Symptoms & No. (\%) & $\begin{array}{l}\text { Vit } \\
\text { (ng/ml) }\end{array}$ \\
\hline Fever & 36 & 18.5 \\
Cough & 40 & 20.3 \\
Weight loss & 18 & 19.5 \\
$\begin{array}{l}\text { All symptoms } \\
\text { together }\end{array}$ & 18 & 15.8 \\
\hline
\end{tabular}

There was highly significant difference between $\mathrm{Tb}$ patients and healthy individuals regarding smoking, $43.3 \%$ of the patients were smokers compared to $15.4 \%$ in the control group $(\mathrm{p}$. value $=0.004)$. Vit $\mathrm{D}$ concentration was found to be higher in non smokers $\mathrm{Tb}$ patients as well as non smokers in control group. There was a trend of increasing risk of tuberculosis with decreasing consumption of vit $\mathrm{D}$ rich dietary, as it low in individuals infrequently consume meat or fish (p. value $=0.00)($ Table 4$)$.

Table 4: Comparison of Vit D concentration between Tb patients and controls according to some risk factors.

\begin{tabular}{|llllll|}
\hline & \multicolumn{2}{l}{ TB patients } & \multicolumn{2}{l|}{ Healthy controls } \\
& $\begin{array}{l}\text { No. } \\
(\%)\end{array}$ & $\begin{array}{l}\text { Vit } \\
\text { (ng/ml) }\end{array}$ & No. $(\%)$ & $\begin{array}{l}\text { Vit } \\
\text { (ng/ml) }\end{array}$ \\
& & & & \\
\hline Smokers & 26 & 19.2 & 17 & 29.4 \\
& $(43.3)$ & & $(15.4)$ & \\
Non & 34 & 20.4 & 87 & 30.1 \\
smokers & $(15.5)$ & & $(84.6)$ & \\
$\begin{array}{l}\text { Fish/meat } \\
\text { consumers }\end{array}$ & $\begin{array}{l}28 \\
(46.7)\end{array}$ & 20.2 & $102(98)$ & 31.8 \\
$\begin{array}{l}\text { Fish/meat } \\
\text { non }\end{array}$ & 32 & 14.2 & 2 & \\
consumers & $(54.3)$ & & & \\
\hline
\end{tabular}

\section{Discussion}

Vitamin D is important factor in macrophage activation and influence growth of mycobacterium inside it. Several studies show the definitive role of Vitamin D in suppression of proliferation of Mycobacterium and on generalized inflammatory response produced secondary to it (Liu et al., 2007; Martineau et al., 2007).

In this study, we enrolled only newly diagnosed patients who were yet commence treatment as anti-tuberculosis chemotherapy can lower serum Vitamin D levels. Vitamin D, as assessed by 25(OH)2 D3 level, was found to be significantly insufficient in patients with TB, both in male and female. Several previous studies observed an association of $\mathrm{Tb}$ with male sex as higher rates of $\mathrm{Tb}$ were noted in male compared to the female (WHO, 2001; Holmes et al., 1998; Samir, 2011). Of note, a genome-wide linked study suggested a linkage between regions of the human genome containing TB susceptibility genes and chromosome $\mathrm{X}$, which could contribute to the excess of TB in males in many populations (Holmes et al., 1998).

In this study the investigated TB patients had significantly lower mean of 25(OH)D3 compared with healthy subjects, this finding was in accordance with previous studies (Davies et al., 1985; Sita-Lumsden et al., 2007; Talat et al., 2010; Martineau 2012).

Similar to our study, other reports from Tanzania (Friis et al., 2008), Uganda (Davis et al., 2013) and Malawi 
(Banda et al., 2010) show that a low body mass index (BMI) is associated with Vitamin D deficiency in TB patients, this may due to low adipose tissue, as vitamin D stored in adipose tissue. Low BMI is important confounder for association of the low Vitamin D and tuberculosis.

Smoking is a risk factor for tuberculosis, impairment of vitamin D absorption by smoking still unproved but, Smoking causes histological changes in the lower respiratory tract, including vascular intimal thickening, peribronchial inflammation, destruction of alveoli and fibrosis. (Aubry et al., 2000). This leads to impairment of the epithelial function, such as decreased clearance of inhalated substances, reduced ciliary activity, and abnormal vascular and epithelial permeability. Previous studies carried out in Spain revealed that cigarette smoking as an important risk factor for TB (Alcaide et al., 1996; Kolappan \& Gopi, 2002). This study thus supports the hypothesis of earlier studies findings that smokers are more vulnerable to the infection and development of TB, as smoking induces the patho-physiological changes in the lungs (Alcaide et al., 1996; Kolappan \& Gopi, 2002).

There was a trend of increasing risk of tuberculosis with decreasing frequency of consumption of vit $\mathrm{D}$ enriched dietary, inadequate dietary intake indicated a potential lower socioeconomic status of TB patients. Lacto-vegetarian had a higher risk compared with daily meat or fish consumers. "Decreased of immunocompetence associated with vegetarian diet may result in increased mycobacterial reactivation" as cited by Gupta and others in 2009 (Gupta et al., 2009).

\section{Conclusion}

Significant low vitamin D level in TB subjects was. More studies are needed to determine the beneficial of vitamin D supplement for TB prevention and treatment.

\section{References}

Alcaide, J., Altet, M. N., Plans, P., et al. (1996), "Cigarette smoking as a risk factor for tuberculosis in young adults: A case-control study", Tubercle and Lung Disease 77, 112-6. doi: 10.1016/S0962-8479(96)90024-6

Aubry, M. C., Wright, J. L. \& Myers, J. L. (2000), "The pathology of smoke-related lung diseases", Clinics in Chest Medicine 21, 11-35. doi:10.1016/S0272-5231(05)70005-8

Banda, R., Mhemedi, B., Allain, T. (2010), "Prevalence of vitamin D deficiency in adult tuberculosis patients at a central hospital in Malawi", International Journal of Tuberculosis and Lung Disease 15(3), 408-10. PMID: $\underline{21333112}$

Bellamy, R., Beyers, N., McAdam, K.P.W.J, Ruwende, C., Gie R., Samaai, P., Bester, D., Meyer, M., et al. (2000), "A genome-wide search for tuberculosis susceptibility genes in Africans", Proceedings of the National Academy of Sciences of the United States of America 97, 8005-09. DOI: 10.1073/pnas.140201897

Borkow, G., Weisman, Z., Leng, Q., Stein, M., Kalinkovich, A., et al. (2001), "Helminths, human immunodeficiency virus and tuberculosis", Scandinavian Journal of Infectious Diseases 33, 568-71. Doi: $10.1080 / 003655401753382512$

Davies, P.D.O., Brown, R.C. \& Woodhead, J.S. (1985), "Serum concentration of vitamin D metabolites in untreated tuberculosis", Thorax 40(3), 187-90. doi:10.1136/thx.40.3.187

Davis, K., Edrisa, M., Richard, S., William, W. (2013), "Vitamin D deficiency among adult patients with tuberculosis: a cross sectional study from a national referral hospital in Uganda", BMC Research Notes, 6, 293. doi:10.1186/1756-0500-6-293

Friis, H., Range, N., Pedersen, M. (2008), "Hypovitaminosis D is common among pulmonary tuberculosis patients in Tanzania but is not explained by the acute phase response", The Journal of Nutrition, 138, 2474-80. doi:10.3945/jn.108.094979

Gupta, K.V., Gupta, R., Atreja, A., Verma, M., Vishvkarma, S. (2009), "Tuberculosis and nutrition", Lung India 26, 9-16. DOI: $10.4103 / 0970-2113.45198$

Hmama, Z., Sendide, K., Talal, A., Garcia, R., Dobos, K., Reiner, N.E. (2004), "Quantitative analysis of Phagolysosome fusion in intact cells: inhibition by mycobacterial lipoarabinomannan and rescue by an 1alpha,25dihydroxyvitamin D3-phosphoinositide 3-kinase pathway", Journal of Cell Science 117, 2131-40. DOI: $\underline{10.1242 / \text { jcs. } 01072}$

Holmes, C.B.1., Hausler, H., Nunn, P. (1998), "A review of sex differences in the epidemiology of tuberculosis", 
International Journal of Tuberculosis and Lung Disease 2(2), 96-104.

Jones, B., Young, S., Antoniskis, D., Davidson, O., Kramer, F. \& Barnes, P. (1993), "Relationship of the manifestation of tuberculosis to CD4 cell counts in patients with human immunodeficiency virus infection", American Review of Respiratory Disease 148: 1292-97. DOI: $\underline{0.1164 / \mathrm{ajrccm} / 148.5 .1292}$

Kolappan, C. \& Gopi, P.G. (2002), "Tobacco smoking and pulmonary tuberculosis", Thorax 2, 57:964-966. doi:10.1136/thorax.57.11.964

Kramnik, I., Dietrich, W.F., Demant, P., Bloom, B.R. (2000), "Genetic control of resistance to experimental infection with virulent Mycobacterium tuberculosis", Proceedings of the National Academy of Sciences of the United States of America 97(15), 8560-8565. DOI: 10.1073/pnas.150227197

Kumar, V., Abbas, A.K., Fausto, N., Mitchell, R.N. (2007), Robbins basic pathology. 8th ed. Philadelphia: Saunders Elsevier; 516-22

Lee, J.S., Yang, C.S., Shin, D.M., Yuk, J.M., Son, J.W., Jo, E.K. (2009), "Nitric oxide synthesis is modulated by 1,25-Dihydroxyvitamin D3 and interferon-gamma in human macrophages after Mycobacterial infection", Immune Network 9(5), 192-202. DOI: $\underline{10.4110 / \text { in.2009.9.5.192 }}$

Liu, P.T., Stenger, S., Tang, D.H., Modlin, R.L. (2007), "Cutting edge: Vitamin D-Mediated human antimicrobial activity against Mycobacterium tuberculosis is dependent on the induction of cathelicidin", Journal of Immunology 179(4), 2060-63.

Martineau, A. (2012), "Old wine in new bottles: vitamin D in the treatment and prevention of tuberculosis", Proceedings of the Nutrition Society 71, 84-9. doi:10.1017/S0029665111003326

Martineau, A.R., Wilkinson, K.A., Newton, S.M, Floto, R.A., Norman, A.W., Skolimowska, K., et al. (2007), "IFN gamma- and TNF-independent Vitamin D inducible human suppression of mycobacteria: the role of cathelicidin LL-37", Journal of Immunology 178 (11), 7190-98.

Rook, G.A., Zumla, A. (2001), "Advances in immunopathogenesis of pulmonary tuberculosis", Current Opinion in Pulmonary Medicine 7, 116-23. DOI: 10.1097/00063198-200105000-00002

Samir, M. A. (2011). Behavioral pattern of tuberculosis in Sudan from 1995 through 2009. Sacha Journal of Environmental Studies, (1), 69-81

Sita-Lumsden, A., Lapthorn, G., Swaminathan, R., Milburn, H.J. (2007), "Reactivation of tuberculosis and vitamin D deficiency: the contribution of diet and exposure to sunlight", Thorax 62(11):1003-7. doi: $10.1136 /$ thx.2006.070060

Talat, N., Perry, S., Parsonnet, J., Dawood, J., \& Hussain, R. (2010), "Vitamin D Deficiency and Tuberculosis Progression", Emerging Infectious Diseases 16(5), 853-855. doi: $\underline{10.3201 / \text { eid1605.091693 }}$

Waters, W.R., Palmer, M.V., Nonnecke, B.J. (2004), "Mycobacterium bovis infection of vitamin D-deficient mice", Microbial Pathogenesis 36(1), 11-7. DOI: $\underline{10.1016 / \text { j.micpath.2003.08.008 }}$

World Health Organization WHO (2015), Global tuberculosis report. Geneva. 